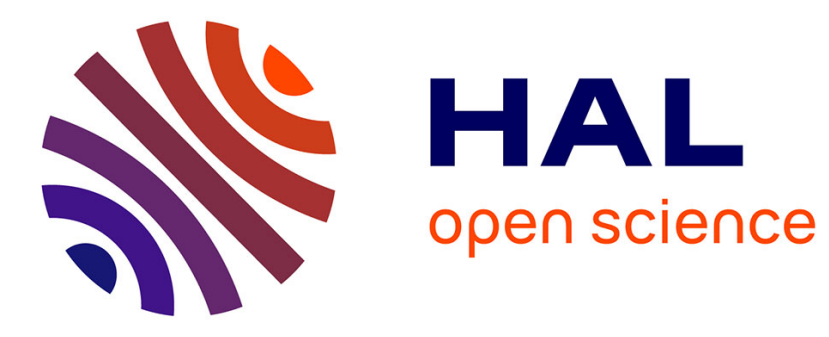

\title{
Aristotle and Linearity in Substance, Measure, and Motion
}

Paul Taborsky

\section{To cite this version:}

Paul Taborsky. Aristotle and Linearity in Substance, Measure, and Motion. Axiomathes, 2021, 10.1007/s10516-021-09586-z . hal-03347144

\section{HAL Id: hal-03347144 \\ https://hal.science/hal-03347144}

Submitted on 17 Sep 2021

HAL is a multi-disciplinary open access archive for the deposit and dissemination of scientific research documents, whether they are published or not. The documents may come from teaching and research institutions in France or abroad, or from public or private research centers.
L'archive ouverte pluridisciplinaire HAL, est destinée au dépôt et à la diffusion de documents scientifiques de niveau recherche, publiés ou non, émanant des établissements d'enseignement et de recherche français ou étrangers, des laboratoires publics ou privés. 


\section{Axiomathes \\ Aristotle and Linearity in Substance, Measure, and Motion --Manuscript Draft--}

Manuscript Number:

Full Title:

Aristotle and Linearity in Substance, Measure, and Motion

Article Type: Manuscript

Keywords:

Aristotle; unity; linearity; continuity; contraries; motion; formal models

Corresponding Author:

Paul Taborsky

Centennial College

Toronto, CANADA

Corresponding Author Secondary Information:

Corresponding Author's Institution: Centennial College

Corresponding Author's Secondary Institution:

First Author: Paul Taborsky

First Author Secondary Information:

Order of Authors:

Paul Taborsky

Order of Authors Secondary Information:

Funding Information:

Abstract:

The model of a closed linear measure space, which can be used to model Aristotle's treatment of motion ( kinesis ), can be analogically extended to the qualitative 'spaces' implied by his theory of contraries in Physics I and in Metaphysics lota, and to the dimensionless 'space' of the unity of matter and form discussed in book Eta of the Metaphysics. By examining Aristotle's remarks on contraries, the subject of change, continuity, and the unity of matter and form, Aristotle's thoughts on motion, on contraries, and on the unity of substance can be brought together under a single interpretive framework, which can provide an approach to interpreting his ontology. 
Title: Aristotle and Linearity in Substance, Measure, and Motion Author: Paul Taborsky

Affiliation: Centennial College, Toronto, Ont.

Email: pdtaborsky@yahoo.ca 


\section{Aristotle and Linearity in Substance, Measure, and Motion.}

\section{Table of Contents}

1 Introduction: Linearity-Physics 7.5-The Critique of 'One-Over-Many'-Matter and



1.1 The orientation of Aristotle's critique of unity, movement, and measure ...............................1

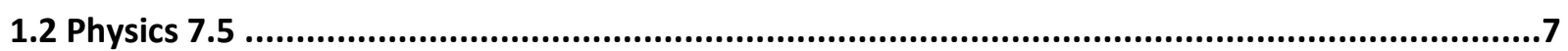

1.3 The 'one over many' argument and many-one relations ................................................10

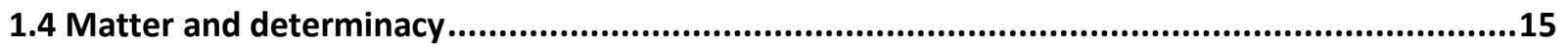



2.1 Aristotle's theory of contraries: contraries as endpoints in a linear measure space ..................18

2.2 A mathematization of the measure space: motions and limits ...............................................30

2.3 The dimensionless space of composite being: the unity of matter and form ..........................42

3 Conclusion: The Linearity of Being and the Unity of Metaphysics ................................ 46



1 Introduction: Linearity_Physics 7.5—The Critique of 'One-Over-Many'—Matter and determinacy

\subsection{The orientation of Aristotle's critique of unity, movement, and measure}

I would like to argue for the existence of a particular 'motif' in Aristotle, a motif which, to my mind, throws light on what we might say Aristotle is trying to accomplish in a number of his central works that deal with the reality or make-up of the world. I believe that understanding this motif, or better, perceiving its presence in the Aristotelian corpus, helps us to understand what 
for want of a better word may be called Aristotle's metaphysical 'orientation'. The motif is that of a linear measure space.

I contend that the model of a linear measure space can throw light on a number of key facets of Aristotle's treatment of being and of the make-up of the physical world. The first of these, most obviously, concerns that of motion $^{1}$ (kinesis). Aristotle's treatment of motion, his 'rational mechanics', has been explicitly analyzed in terms of a bounded or finite Euclidean kinematical 'space' by White (1992), and as an anticipation of Newtonian kinematics by Hussey (1983).

There is much that could be said about both of these interpretations; however, my point here is not to argue either for or against the general perspicuity of either of these reconstructions of Aristotelian physical theories (although I do borrow much from White (1992), especially in the second part of what follows), nor do I have much to say about to what extent Aristotelian kinematics can reconstructed as an anticipation of modern (Newtonian) kinematics. I only hope to show that for Aristotle, as has been stressed by De Groot (2014, pp. 14, 75-81), and earlier by Crubellier (1997, 2005), mathematical structures can be inherent in certain cognized phenomena

\footnotetext{
${ }^{1}$ The Greek 'kinesis' has a broader semantic range than the English 'motion', as it also encompasses alteration and growth, i.e., qualitative as well as quantitative change. It is sometimes translated as 'change', 'movement', or 'process', depending on the context. I stick with the traditional translation as I believe it best conveys key aspects of the Aristotelian conception, as will become apparent.
} 
(as opposed to the traditional view that for Aristotle mathematical quantities are obtained by abstraction from phenomena); in the case of the phenomena under consideration here, the structure is that of linearity ${ }^{2}$.

For my purpose much of interest occurs when we try to extend the reach of this model beyond an analysis of the Aristotelian physics of motion. I believe that this model can serve as a kind of heuristic which can illuminate aspects of other areas of Aristotle's thought, in particular, his treatment of the metaphysics of polarity or contraries, and his attempts at articulating and solving the problem of the unity of matter and form in substance, both of which lie close to

${ }^{2}$ My own interpretation of this formal aspect differs somewhat from both that of De Groot and Crubellier; the former adopts a reading (with roots in Husserl) that (for Aristotle) mathematical structure is inherent in certain experiential phenomena; in this way, her reading has much in common with the realist (but not phenomenological) orientation of White and Hussey. Crubellier holds a much more 'orthodox' interpretation in that he holds that such mathematical structures, although in a certain sense constitutive of reality, play at most a dialectical role for Aristotle, in that they lead to, but do not fully constitute, an analysis of what 'being' is. My own reading differs somewhat from both; unlike De Groot, I believe that, for Aristotle, linearity is not confined to certain phenomena (nor even to phenomena at all). In contrast to Crubellier, I am willing (much as De Groot is) to countenance a non-dialectical role for formalism in Aristotle. However, I believe (with Crubellier, I assume) that such formalism is more indicative of Aristotle's philosophical approach than it is of "one historical vector extending out from a core universal knowledge process" (De Groot, p. 365). For details see sections 1.4, and 2.1, below. 
Aristotle's key project of a 'science of being as being', as announced in book Gamma of the Metaphysics. Judson (2019, p. 136) has suggested that some sort of convergence between the Aristotelian theory of contraries ${ }^{3}$ and that of substance, a possibility hinted at in some passages in chapters 4 and 5 of book Lambda of the Metaphysics, "promises to solve the problem of the unity of first philosophy in a way that the ideas of focal meaning and the priority of substance cannot by themselves do.' I take this suggestion as encouragement that the sort of approach to Aristotelian first philosophy proposed here may not be misguided.

Extending the model will also enable us to understand in what sense Aristotle's rational kinematics fits into his general project or orientation towards the above mentioned problem of being, or at least to get a better grip on it than has often been the case. To mention two of the authors cited so far: for White, Aristotelian kinematics, especially when contrasted with the kinematics of the Stoics and the Epicureans, illustrates, at best, Aristotle's familiar via media approach to a number of issues; in the case of motion, that would be the via media of a theory that tries to integrate both the continuous and discrete aspects of physical reality into a single comprehensive approach ${ }^{4}$. White also claims (p. 328) that something of this integrative aspect

\footnotetext{
${ }^{3}$ Insofar as contraries can be included under the non-substantial categories. See also section 2.1, below.

${ }^{4}$ I don't doubt that this is the case; indeed I draw on this idea. I simply believe that it follows from Aristotelian commitments other than those of empiricism or a kind of mean-seeking approach occasionally claimed to be a hallmark of Aristotelianism. In this regard, see also De Groot's criticism (op. cit., pp. 74-81) of the view that Aristotle's method in natural philosophy is
} 
can be seen in Aristotle's central metaphysical ideas, that is, a valuation of a world that consists of both discrete substances on the one hand, and collectivities such as natural kinds, on the other. Hussey (p. x) claims, in a somewhat similar vein, that Aristotelian physics is primarily an expression of Aristotle's 'general metaphysical position', one that is 'essentialist, realist, and anti-Platonist', and largely committed to exposition of what might be called the manifest image of the world. By emphasizing the 'ecumenist' aspect of Aristotle's approach — a middle between the two extremes of the two Hellenistic schools, one emphasizing continuity (the Stoics), the other, discreteness (the Epicureans), White seems to be following the same line of thought as Hussey.

There is some truth to both of these claims, but I believe that there is more that can be said about how Aristotle's kinematics completes, or exemplifies, his metaphysical approach, one that draws on rather more than the familiar tropes of the Peripatetic philosophy as an empirical, 'common sense' philosophy of the manifest image. This, I would claim, is the specific thesis of linearity, an aspect of Aristotle's thinking that has been neglected (or even obscured or denied) even more by another interpretive trend, and that is the (or one) current intellectual trend that envisions Aristotle as the champion of a philosophical approach that can be broadly characterized as anti-reductionist, anti-materialist, and in some way or another opposed to what

driven by a coherentist ('endoxic') and 'dialectical' adjudication of the inherited scientific tradition, an idea associated with the work of G. E. L. Owen and Martha Nussbaum. For my explanation (that Aristotle's integration of the continuous and the discrete is a consequence of linearity), see section 2.1 below. 
might be called the 'mechanical world picture' ${ }^{5}$. The first of these tropes (in White and Hussey) is no doubt accurate to a degree, but misses much of what is of particular philosophical interest in Aristotle. For one, it is surely correct to claim that a move towards concrete empiricism and realism of some sort characterized a great deal of philosophical thought after Aristotle, especially in the schools of the succeeding Hellenistic era, so in this sense Peripatetic philosophy is not unique, even in antiquity, in paying attention to or theorizing from experience, especially in terms of the manifest image. Secondly, the perennial, almost pre-philosophical existence of some sort of common sense manifest image is at least a debatable concept, and it is especially questionable whether a worked out philosophical theory such as Aristotle's (or that of any other thinker) could ever be free of other assumptions (my point, to anticipate, is that linearity is one such assumption, an assumption that is not continued by the succeeding Stoic and Epicurean schools).

The second interpretative trope, that of Aristotelianism as a kind of paragon of an antimechanical outlook, is in need of a certain amount of reconsideration. The idea that Aristotelian philosophy is not inherently hostile to mechanism has in fact been argued for in various ways by Balme (1939 \& 1941), Berryman (2009), and De Groot (2014), among others. Although there are important differences between mechanical theories and theories of linear interaction (not all

\footnotetext{
${ }^{5}$ For a sample of this kind of thinking, see the preface to Lennox (2001), p. xx., where Aristotle's biological thought is contrasted with modern biology's development out of a 'Christian-Cartesian philosophical context of inert material body and active, immaterial soul'.
} 
mechanical interaction is linear ${ }^{6}$, and not all linear functions or forces are mechanical), by showing that in important ways Aristotelian metaphysics (and not simply physics) can be said to thematize a certain kind of linear interaction, I hope to contribute something to this reconsideration.

\subsection{Physics 7.5}

That linearity has implications, or foundations in Aristotle's thought beyond that of kinematics can be developed by means of two texts in the Physics. Near the end of Physics 7.5, a brief chapter which contains, as pointed out by Sambursky (1962, p. 65), Aristotle's only mathematically explicit formation of what might be called a law of motion, there are two hints that indicate that such a more generalized approach might be warranted. First, in commenting on the apparent need for natural limits or thresholds to physical forces (in the specific case of what has become known as the 'ship hauler' problem), Aristotle brings up a particular example of a 'Sorites' paradox, or the paradox of the heap, a group of paradoxes from antiquity that deal with the make-up of large accumulations of discrete items, such as hairs or grains of sand. The particular version mentioned by Aristotle has been called the paradox of the 'millet seed', for it runs as follows: if a heap of millet seeds makes a sound upon falling, it follows that a falling single millet seed should make a sound; yet no sound is heard.

Aristotle uses this paradox to explain why forces must have natural thresholds or limits: in the same way that the fall of a single millet seed is not audible, though the collection of seeds

\footnotetext{
${ }^{6}$ For example, stress and shear forces in continuum mechanics ( $c f$. Truesdell (1968, pp. 352-3)). See note 27 below for a more precise definition of linearity.
} 
is, a single person cannot haul a ship, though a group of ship haulers might. There are various ways one might interpret Aristotle's response to the paradox, but what is of interest here to me is why the millet seed paradox has been brought in to illuminate the ship hauler problem in the first place.

For on the face of it, falling millet seeds would seem to have little relevance to the forces involved in moving a ship. Sambursky (op. cit., p. 66) has remarked that the ship hauler problem and its solution by Aristotle point to, among other things, a general ignorance of the reality of frictional forces in antiquity. Since Aristotle was unaware of the need to take account of the reciprocal action of frictional forces that hinder the movement of pulled or dragged objects, he was forced to postulate limits within the pulling forces themselves, to explain the lack of motion when a single man tries to move a ship.

Yet the sound of falling millet seeds, quite obviously, has nothing to do with frictional forces, so they appear to manifest a very different kind of physical situation than that of the grounded ship. Nor are the sounds of millet seeds directly comparable to the pulling or dragging forces of the ship haulers themselves. Yet Aristotle brings in the former as an explanation of the presence of limits in the latter, despite the very different array of physical forces involved. The explanation of what I take to be the real significance of the presence of this argument in Physics 7.5. is covered in section 2.2 , below.

The second 'hint' in 7.5. is Aristotle's explicit suggestion that the quantitative analysis of physical situations can be broadened to apply to cases where no quantitative measures are 
involved. All that is necessary is that a single quantitative measure have a measurable effect, for in such cases, the laws of proportionality, already outlined earlier in the chapter, will still apply. I argue that such an analysis can illuminate Aristotle's treatment of contraries_-opposites such as hot and cold, many and few, or odd and even, a domain of action inherited from the ancient Greek physical tradition. Aristotle's revisions to this tradition, initially in the first book of the Physics, and later in book Iota of the Metaphysics, can be envisioned as extensions (or more properly, restrictions) of the linear measure space explored in his treatment of motion, to the qualitative domain of polarity or contrary qualities. Aristotle's earlier and later reworkings of the theory transform a hierarchically organized domain of underlying strata and overlying principles (the hierarchy of which can be seen in later Middle Platonic elaborations of the metaphysical principles of the 'one' and the 'unlimited dyad') into a linear domain of notional measure.

Finally, I shall explore how Aristotle's solution to the problem of the unity of matter and form in substance, the subject of book Eta of the Metaphysics, can be linked to the structure of linear space. Matter and form, as Aristotle explains in a passage in book Lambda of the Metaphysics, share certain analogical features with what he has priorly identified as principles of action, the contraries, in particular the primary contraries, to which all others can be reduced: privation and possession. Thus, in my view, proximate matter and form, analogically similar to contraries, can be interpreted as immediate end points of a kind of degenerate space that lacks intermediate points, points which are (virtually) present in both motion and the qualitative or intensive space of contraries. But, although part of a reduced or dimensionless hylomorphic 'phase' space, matter and form are not thereby identical — they can be interpreted as 'touching', continuous but distinct, as will become apparent when the ancient concept of 
continuity is contrasted with the modern and more familiar 'Dedekind continuity' which rules out such kinds of touching. Proximate matter and form can then be understood as correlative end points in a kind of dimensionless space of contraries, having lost intermediate points, but preserving linearity by means of the one-one relationship between proximate form and matter, which is preserved by the correlative relationship of matter and form.

Before I turn to a more detailed examination of these issues, I would like to motivate the discussion from another direction, that is, Aristotle's critique of the Platonic relation of participation. I will examine this issue by means of one particular argument against the Platonic theory of forms.

\subsection{The 'one over many' argument and many-one relations}

Aristotle had a number of objections to the Platonic theory of forms, or better put, to a number of Plato's arguments for the theory. Some of these have come to be known as the 'third man' argument, the 'one over many' argument, the 'flux' argument, the 'argument from opposites' (Annas, p. 153), among others. What was the gist of Aristotle's objections? Cicero writes ${ }^{7}$ that Aristotle 'undermined' the theory of forms; the meaning of Cicero's charge is uncertain. Sometimes it is said that Aristotle brought the Platonic forms 'down to earth', a locution that imputes something of the vaguely empirical orientation to Aristotle, mentioned above, but little more. Contemporary 'anti-Platonism' (in the philosophy of mathematics, for example) is usually taken as an argument or set of arguments against the existence of a separate realm of unchanging

\footnotetext{
${ }^{7}$ Academici Libri I. 33.
} 
objects, an objection that has an empirical 'flavour', one might say. Was this Aristotle's motivation, or one of his motivations (I do not deny that something like this might be a consequence)? — was Aristotle an anti-Platonist in the modern sense?

It would seem that it could not be the case that Aristotle would object entirely to a realm of separate, unchanging objects, for there was in fact such a realm in the Aristotelian cosmos, the realm of celestial objects. The stars and the planets, and their corresponding spheres and unmoved movers, were precisely these kinds of objects, so it is manifestly not the case that Aristotle objected tout court to such a notion ${ }^{8}$.

It might be objected that Aristotle was only an anti-Platonist in the realm of intelligible objects, not in the physical realm (as is indeed contemporary anti-Platonism). But then, again, we might ask to what extent a thought thinking itself, which is what on some interpretations entirely constitutes Aristotle's 'first mover', could be said to be part of the physical universe. Still, whatever the first mover, and other such beings may be, it seems clear that they must be understood as particular beings, not universal entities - this, it seems, must be the force of Aristotle's objections. Some have indeed claimed that Aristotelian forms must be understood to

\footnotetext{
${ }^{8}$ A point stressed by Aubenque (1962), who writes (p. 314), "Separation [between the unchanging and the changing] didn't disappear with Aristotle; it increased in becoming 'physical', henceforth opposing an ordered world to a contingent world, in place of making the ideal order the order of this world" (my translation, italics original).
} 
be particular entities as well. But to claim that separate, eternal objects must be particular, if they exist, is not an objection motivated by empirical considerations.

The point I am attempting to make is that Aristotle's objections to the Platonic one-overmany argument do not correspond to similar arguments made from the standpoint of a contemporary anti-Platonism, a viewpoint which is largely motivated, I would speculate, by a conviction that unchanging objects cannot or do not form the basis of reality (what one might call an anti-substantialist perspective). Instead, Aristotle's objections are motivated by a different thought (I would conjecture), the thought that there cannot be, or are not, real many-one ${ }^{9}$ relations in reality; that is, that the existence of something like a Platonic form, which is a real entity that is related to or is directed to an unrestricted multiplicity of real beings, through the relation of participation, is not possible; not because such a form is an object separated from the realm of temporally existing objects that are taken to make up the reality of common experience, nor because of any reservations about the concept of substantiality itself, but because of an objection to the reality of the peculiar kind of relation that such a being is involved in, that is, the participation relation. This is not an argument motivated either by anti-substantialism (Aristotle, after all, believed in the primacy of substance), nor is it an argument from experience, as the conviction of Aristotle's that real many-one relations are problematic does not appear to rely on what a later age would be called a posteriori judgements. Indeed, Aristotle claims (Metaphysics

\footnotetext{
${ }^{9}$ In the following, 'many-one' refers to all relations which are not bijections, whether these be 'one-many' relations such as between an exemplar and its exemplifications, or strictly many-one, such as the inverse containment relation between part and whole.
} 
Iota, 1056b 4-5) that if the many is placed in a relation of contrariety to the one, 'impossible

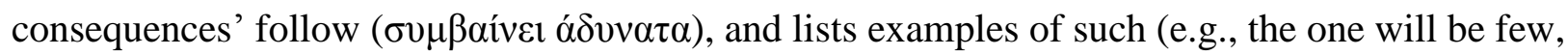
as many is also opposed to the few) which are clearly logical arguments.

So, instead of presenting us with an empirical or empirically motivated argument against the existence of unchanging objects, Aristotle is in fact arguing against the real existence of a certain kind of relation, that of the many-one relation, a relation that Platonic forms instantiate by means of the relation of participation. Moreover, in Aristotle's own thought, the matter-form relation within substance will turn out to be, as I will attempt to show (section 2.3), precisely a particular kind of one-one relation. Many-one relations, should they exist, can only take place between a universal and its instantiations, not between two equally real beings. Thus, the manyone relation is pushed into the realm of a purely logical or conceptual existence, out of the realm of existing things.

That this is a plausible interpretation of Aristotle's critique of the Platonic theory of forms has been argued forcefully by Zingano. Zingano (2005, p. 113) points out that, for Aristotle, in contrast to Plato, there can exist forms of unique objects such as the Sun, the Moon, or the Cosmos, unlike the Aristotelian universal, and the Platonic form, which by definition are able to be predicated of unrestrictedly many objects. For Zingano, the key difference between the Platonic and Aristotelian conception of form is not to be understood in terms of separability or inseparability, nor transcendence vs. immanence, but in terms of unrestricted vs. restricted predication. Thus, for Zingano, 
Aristote lie définitivement le rejet de la doctrine platonicienne à une reconsidération du rôle de l'universel et de la forme comme prédicats. Cette reconsidération n'a pas été pourtant suffisamment mise en valeur. Aristote est souvent présenté comme celui qui a

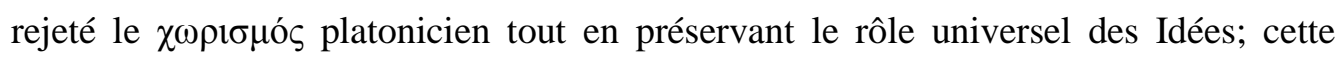
interprétation a trouvé chez Zeller peut-être son meilleur représentant. (p. 129) ${ }^{10}$

Such an interpretation of the distinction between form and universal / Idea in terms of the logical structure of predication (as opposed to Zeller's focus on the issue of a separable realm of Ideas), is not, I would claim, an empirical argument, but a purely philosophical one, for in what sense can a preference for one-one relations as opposed to many-one be based on judgements from experience?

Perhaps it might be replied that the judgement that only concrete individuals truly exist, which traditionally has been presented as a cornerstone of Aristotle's philosophy, could be seen as an eminently empirical judgement, and one that ultimately grounds his rejection of real manyone relations. Yet it is questionable to what extent such a position is really central to his

10 'Aristotle categorically ties the rejection of the Platonic doctrine to a reconsideration of the role of the universal and form as predicates. This reconsideration has perhaps not been sufficiently appreciated. Aristotle is often presented as having rejected Platonic separation, while preserving the universal role of Ideas. This interpretation likely finds its best representative in Zeller.' (my translation). Zingano notes that Zeller's interpretation is now found 'almost everywhere' (p. 130, n. 55). 
philosophy, as his earlier position in the Categories, which did explicitly postulate that only individual, particular things could be primary substances, underwent modifications in the Metaphysics and Physics when the hylomorphic analysis of matter and form introduced important modifications to the earlier picture ${ }^{11}$. The Metaphysics concludes that form is the best candidate for the being of substance, and it is at least debatable as to whether form is to be understood as universal or particular, or even as something else entirely.

\subsection{Matter and determinacy}

Be that as it may, how can we make sense of the claim that the concept of a linear measure 'space' (in the mathematical sense of space) can be justifiably claimed to be 'Aristotelian'? If we recall that matter in Aristotle's natural philosophy is first introduced (in

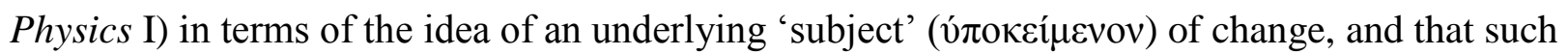
a subject has been argued to be both 'complex' (Morison) and 'functional' (Morel, p. 40), we can see how such a supposition may be conceivable.

Let us turn to Book Eta of the Metaphysics. At the end of the first part of Book Eta, Aristotle lays out the circumstances in which it can be said that matter-excluded from consideration in the preceding discussion of candidates for substantiality in Z3 - may in fact be a 'primary way of being' in a certain sense. Matter can be said to be so by persisting in change between contraries in the form of a persisting underlying subject (v́ can occur in four types of change: change in location, quantitative change, qualitative change, and substantial change (1042a 32-36). Now, the idea that there may be an underlying subject to

\footnotetext{
${ }^{11}$ For the modification thesis, see e.g. Frede (1987), 25-27.
} 
change in location (involving what has at times been called 'topical matter') has puzzled commentators (Furth $(1985$, p. 126) calls it a 'retrograde idea' possibly brought in from earlier work in the Physics); nevertheless, as Morel (p. 37) has pointed out, in this passage in Eta an important point is being made, a point that arguably represents a development and advance of the conception of matter from the preceding book Zeta: that matter, far from being a mere passive indeterminate structure, may yet serve as a means of revealing 'functions and aptitudes' of the particular domain of change in which it appears. Matter, in its role as a substrate or underlying subject may thus be more than a simple indeterminate substrate, but may 'at the same time be both partially determinate and determinable' (Morel, p. 39).

If this is a plausible interpretation, I would argue that this makes my claim that the space of change in Aristotle may be conceived of as a linear measure space, slightly more conceivable. If the 'subject' or underlying matter of change can possess, or perhaps, less objectionably, determine structure, it may well be conceived as able to 'admit of' or be spoken of as possessing the structure of a linear measure. In fact, I would claim that it is precisely due to this linearity that matter may share in a certain measure of existence or 'primary being' (to use Hope's locution). This can be illustrated by the following schema (the arrows indicate ontological grounding):

\section{Linearity $\rightarrow$ Identity $\rightarrow$ Existence.}

That is, in the 'space' of Aristotelian change or substantial unity, it can be said that 'there is' an underlying subject (or unity) in the same way that there exists a unique path between two 
points in Euclidean space. In Euclidean space there is one and only one minimal straight line between two points. Such a uniqueness condition gives the line or path identity, and in that way existence (for comparison, we can say there 'is' a straight line between two points because in Euclidean space there can, and must be, only one). Thus we can say that the underlying 'subject' ${ }^{\prime 2}$ in the Aristotelian spaces concerned owes its existence to its uniqueness, which is further a consequence of the linearity of the domain under concern. Aristotelian matter can therefore be said to partake of primary being and hence to 'exist' (in some sense or another) due to purely 'formal' considerations, but in terms of a formality quite different from the standard Aristotelian notion of form.

\section{Measure, Motion, and Unity}

Reversing the explanatory order from part one somewhat, I shall begin this section with an exposition of how a linear model can be exemplified by Aristotle's revisions to the theory of contraries. Realization of this model in a quantifiable domain, that of motion in space, or locomotion, involves not only the additional factor of a publicly observable standard of measure, but also the mathematical concepts of limits and continuity. Understanding the particular conception of continuity employed by Aristotle, specifically its divergence from the more

\footnotetext{
${ }^{12}$ Conceived of in the 'complex' way of Morison, as consisting of both subject and privation, or in terms of grounding the unity of (proximate) matter and form, to be discussed below (section 2.3).
} 
familiar modern conception, will help us understand some particular features of Aristotle's solution to the problems of the unity of matter and form as discussed in book Eta of the Metaphysics, especially how correlativity - the aspect of linearity which is pertinent to hylomorphic unity — characterizes the matter form relationship in substance.

\subsection{Aristotle's theory of contraries: contraries as endpoints in a linear measure space}

Aristotle's revisions to the theory of contraries, inherited from the earlier philosophical tradition, can be encapsulated by the following: 'The one is opposed to the many as measure to measurable; and these are opposed as those relatives which are not relative in their own right' (Metaphysics, Book Iota, 1056b 33-35). In brief, Aristotle conceives of the 'one' (or unity) as a unit of measure, and hence not a contrary itself; the particular case of one-many opposition becomes, in Aristotle's revision, opposition between the few and the many, while the terminus a quo of the older theory now becomes that which constitutes a measure of the few-many domain, and hence not a true relative.

To recapitulate: the theory (or theories) that Aristotle was attempting to revise posited contraries (enantia), such as the hot and the cold, the odd and the even, or the many and the one, as pairs of opposed principles that in some fashion or another operate as principles of being. From Aristotle's comments in $\Gamma 2$ of the Metaphysics (1004 a9-b8), we can see that he intended, in some way or another, to preserve this relationship, that is, the relationship between his proposed 'science of being as being', introduced in book Gamma, and the principles of contraries, inherited from the older Greek tradition of natural science. 
There are clearly a number of conflicts that might arise between a substance-oriented theory of being such as Aristotle's and a theory of natural change centred on the interactions between pairs of opposed contrary principles ${ }^{13}$. Aristotle's revisions to the traditional theory may therefore reasonably be understood as an attempt to bridge this problematic. Now, it should be noted that some commentators have claimed that the discussion of contraries and unity in book Iota is purely 'negative', in that it should be understood principally as a critique of Platonic doctrines of number, as in the 'mathematical' books of the metaphysics (Books M and N); yet Castelli claims (2018, p. xxiv) that the contributions of book Iota go beyond a purely negative or 'destructive' critique of Platonic doctrines, and make positive contributions to Aristotle's doctrine of substance and being, despite the paucity of discussion of substance in that book. That being said, Castelli reminds us that the discussion of unity in these chapters is centred on unity as a quantity or measure (a key point which I shall expand upon shortly), not unity in terms of the unity of being or substance, while the discussion of contraries is focused on pairs of opposite qualities, not quantity. What then could be the connection between the Aristotelian proposed science of 'being as being' and the theory of contraries and the discussion of unity therein?

${ }^{13}$ Lefebvre (p. 295) notes (in reference to the discussion in Metaph. Г2, noted above.): “The new Aristotelian metaphysics consists exactly in the thought that contraries are insufficient for explaining becoming.” (My translation.) The idea is an old one. As noted by Judson (2018, p. 132, n. 11), Simplicius was forced to concede that form and privation could not, contrary to the direction of Aristotle's discussion in Physics I, be understood as contraries, but must be characterized 'in some other way'. 
Castelli's solution, based on a passage in $\Lambda 4(1070 \mathrm{~b} 16-20)^{14}$, is that, without trying to equate them, the two approaches can be seen as complementary approaches in Aristotle's metaphysics. She suggests that 'both ideas play for Aristotle a fundamental role in determining the formal constraints for an appropriate description of being.' (p. xliv).

We might at this point ask what a 'formal constraint' could be for Aristotle, or how the idea of a complementary approach might be filled out. A number of writers have, in fact, stressed the existence of 'formal' considerations in Aristotle's treatment of contraries, and that such considerations may help to clarify the relationship between Aristotle's analysis of contraries and that of substance, and thence the unity of 'first philosophy' as proposed in Г2. Lefebvre (2008), for example, has dealt with Aristotle's use of the concept systoichia (co-ordination, correspondence) and its role in organizing and categorizing the contraries by means of an organizing list, in a manner distinct from the familiar Aristotelian concept of 'focal meaning'. Delcomminette (2019, p. 186), commenting on Lefebvre, emphasizes the formal aspect of this analysis in isolating the 'relation of contrariety itself' ${ }^{15}$ (188), which is also present (as possession and privation) in the hylomorphic analysis of substance. Crubellier (2005, pp. 79-80)

\footnotetext{
${ }^{14}$ This is the same passage noted by Judson (section 1.1, above).

${ }^{15}$ Delcomminette (p. 185) remarks on the 'one-to-one relationship' between items on the list of contraries. Lefevbre (p. 305) employs a spatial metaphor in his elucidation of systochia: 'Systoichia primarily indicates a spatial gathering of elements, and next a co-ordination of its terms within the same column or line' (my translation). This linearity is a key feature which the present essay attempts to extend.
} 
likewise emphasizes the structural and formal aspects of Aristotle's solution to the problem of the unity of first philosophy, as raised and discussed in book Gamma in the Metaphysics. These formal and structural aspects, inherited from the Platonic tradition, allow us to 'describe and think about reality, although not to explicitly account for it' (p. 80, my translation). Such a unity is therefore epistemological, as opposed to ontological (p. 61) ${ }^{16}$, although Crubellier does stress that these aspects are based on 'intelligible relations ${ }^{\prime 17}$ between the constituents of the world, and therefore real. My purpose in the present paper is to build on these promissory notes. Crubellier suggests (p. 80) that Aristotle's analysis of contraries in the Physics brings in considerations from the dialectical tradition to bear on the conceptual organization of physics; I would stress instead Aristotle's naturalistic and physicalist interpretation of this dialectical tradition by means of his own revisions to the theory of contraries outlined in Physics I and book Iota of the Metaphysics, and, just as importantly, in his analyses of motion and substantial unity in other parts of the corpus, analyses that similarly involve objects of experience that incorporate transitions between ends points of a directed process - the leitmotiv of change between contraries. Such an extended analysis will enable a more precise resolution of the problem as well as a more determinate specification of the formal structures involved, I believe, than has so

\footnotetext{
${ }^{16}$ My choice of the word 'motif' to designate the use of what I have termed a linear metric space is motivated by a similar consideration.

${ }^{17}$ Likewise, De Groot (p. 78, n. 133) notes the centrality of the category of relation to her reconstruction of the mathematical structure of the moving radius principle in the Aristotelian Mechanics.
} 
far been carried out (at the cost, admittedly, of employing modern concepts foreign to Aristotle, a cost which may be worth bearing.)

What are the main features of Aristotle's revision to the traditional theory of contraries? The following seem to be the key points ${ }^{18}$ : pairs of contraries have something in common (1054b27), or, in another formulation, the two 'principles' embodied in contraries always are accompanied by a third principle, that can be associated with the substrate of these properties or an 'intermediate nature' ( $\mu \varepsilon \tau \alpha \xi \grave{v})$ (Physics I.6 189b 22 et seq.); as a consequence, contraries do not act on one another (e.g. Physics I.6 189b 22 et seq.); possession and privation are the primary

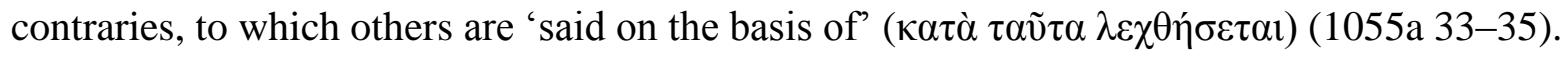
The one is not opposed to the many. Instead, the many is opposed to the few, while the one is the measure of the many and the few, or rather of the underlying substrate, of which the many and the few are the extremes.

In what may be an earlier stage of Aristotle's thought ${ }^{19}$, the first of these points was articulated in terms of the need for a third principle of being in addition to the two sets of principles that many earlier thinkers found in nature. In the opening chapters of the first book of the Physics, Aristotle informs us that earlier thinkers posited that there was either a single

${ }^{18}$ This summary in this paragraph is indebted to Castelli (2018, pp. xxvii et seq.); the conclusions I draw in subsequent paragraphs are my own.

${ }^{19}$ See, for example, Charlton (1970, p. xiii), who reports Ross's opinion that Physics I was likely composed when Aristotle was still a member of the Platonic Academy. 
principle in nature (such as air, or water) or that there were two, in the form of contraries. Aristotle's contribution to this debate is to argue that the number of fundamental principles must be three ${ }^{20}$ : two contraries, which are not however to be identified with fundamental being, and a third, which he will identify with matter or the material principle ${ }^{21}$. In Book Iota of the Metaphysics, the discussion appears to have advanced, in that Aristotle now brings in the additional concept of measure ${ }^{22}$. The 'one' is no longer putatively identified with the substrate

${ }^{20}$ Aristotle's position concerning the number of principles suffers from a certain amount of ambiguity. At Physics I.7 (190b29-30) he writes “Accordingly, fundamental principles are in one sense two, and in another sense three" (tr. Hope). This ambiguity, does not, I trust, affect what follows.

${ }^{21}$ This strategy of Aristotle is evidently an attempt to account for both sets of principles, the 'one' of the naturalists, and the 'two' of the Platonists. In this regard, see Wolff's (2005) interpretation of Aristotle's discussion in Metaph. Z3 as combining the 'physical' and 'logical' accounts of the substrate of these two groups of thinkers, respectively, in a single account of being-as-substrate.

${ }^{22}$ This concept of measure may in fact be present in the earlier account in the Physics, at Physics

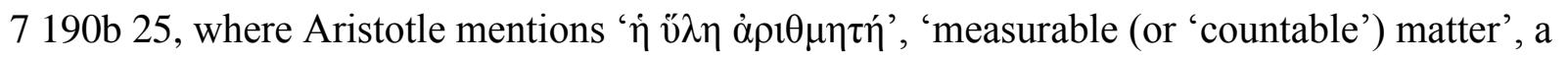


'unorganized' , 'unformed'). In his discussion of this passage, Lorenz (2020, p. 268) (likely following Simplicius) accounts for the phrase in terms of the ability of proximate matter to be 'some this' ( $\tau$ ó $\delta \varepsilon \tau \imath$ ), a 'determinate, reidentifiable something or other', but this seems too quick. Countability is a consequence of quantifiability, not identity. Without further argument, as we 
(i.e. the various 'ones' of the Milesians) but with that which acts as its measure. This imports a quantitative dimension to the material substrate, that is, that matter can be seen as something susceptible to measure.

For Aristotle, the contraries do not act on one another, unlike, for examples, Empedocles' principles of Love and Strife ${ }^{23}$. This is a consequence of Aristotle's repositing (beginning with the initial version of the theory) of the pairs of contraries as end points in a process, the process of change in the intermediary or underlying matter, the movement from privation of form to the possession of form, instead of the supposition that they are primary beings. But in the newer

find in book Iota - extending measurability to the 'space' separating all contraries — it is difficult to make sense of some of Aristotle's examples. A sphere may be made of out of a determinate amount of bronze, as Lorenz claims (using the first example in the passage), but this kind of reasoning seems to be of little use with the passage's other example, that of a musical man. Is a musical man made out of a determinate 'amount' of man, or out of a determinate amount of man qua musical knowledge capacity? The fact that 'man' is countable in the first sense seems to have little to do with the relevance of countability to the discussion. I note that Simplicius' interpretation may have been motivated by his concern to keep his account consistent with the Platonic account of identity, as can be seen by his remarks on this passage at in Physicam 217, $36-218,11$.

23 'Love, for example, does not attract Strife and produce something out of it; or vice versa' (Physics I 6, 189a 24) 
formulation in Iota, these endpoints can also be understood to be the end points in a measurable space $^{24}$, now that the substrate has been identified with something capable of taking on or possessing a measure.

Aristotle's revision of the argument has, as a consequence, the collapse of an ontological hierarchy. In the earlier pictures (that is, the pre-Socratic and Platonic pictures), the 'one' or substrate occupied a different ontological plateau than that of the contraries; the latter, form and privation, supervened ${ }^{25}$ in some manner or another on the substrate. In the newer picture, the one and its endpoints now occupy the same measure space. The measure space of the one as measure and the pairs of contraries have become elements in a linear space, a linear space of change.

${ }^{24}$ For Aristotle's justifications for extending the analysis of quantity to qualitative 'spaces', see section 2.2, below. Hussey (1983, p. 143) explicitly uses the language of modern physics ('phase space, 'natural metric') in his discussion of Aristotle's analysis of qualitative change, so such an analysis is not unprecedented.

${ }^{25}$ I use this rather contemporary concept for the sake of familiarity and convenience. I do not intend to imply that it is an adequate interpretation of Aristotelian hylomorphism at any stage of Aristotle's thought. 
The claim that it is possible to view the 'measurable space' of the range of contraries as linear is, in part $^{26}$, a consequence of Aristotle's assertion that the few, not the one, is contrary to the many, that contraries are not active powers, and that the one must be understood as a measure of contraries, and not as a pole. Linearity, in the context of a single measure or dimension, can only mean additive or multiplicative, rather than exponential growth ${ }^{27}$. It is difficult to draw conclusions from Aristotle's generally non-mathematical approach, but one of the consequences of the replacement of one pole of the one-many relation with the 'few' may likely be such a result.

We saw earlier that Aristotle made use of a Sorites paradox in order to throw light on the problem of the apparent existence of natural limits in the application of force. I believe that the general framework of the paradox can also be of use in understanding Aristotle's theory of contraries, for, on one interpretation of the paradox, the growth of a heap shares structural features with Aristotle's revised picture of contraries.

${ }^{26}$ The existence of a unitary measure is a necessary but not sufficient condition for linearity. A further condition will be explored in the following section.

${ }^{27}$ An operation is linear if it can be decomposed into its elements, i.e. if the operation on a set of elements is equivalent to the composition of individual operations within the set. If composition is written as addition, then the conditions can be written as: $f(x+y)=f(x)+f(y)$, and $f(c x)=c f(x)$, where $c$ is a constant. Clearly, addition and multiplication are linear, but exponentiation is not. 
One of the ways of understanding this set of paradoxes may be to conclude that certain kinds of multiplicity cannot be achieved by linear growth from a single unit, but only from a collection of such units. Thus if grains of sand are added to a single grain, one by one, at no point in the process will the compounded grains of sand become a heap, because addition (or removal) of a single grain is never enough to transition from one (a non-heap) to many. But it is evident that heaps exist. Thus, the process must start with a heap to begin with, and thus with a 'few' grains of sand, rather than a single one; both many and few are part of plurality (pleithos). The point may be that when a quantity that can be discretely measured is involved in something's make-up, such as heaps of sand or grain (which come in discrete units of single grains), growth can only be linear. Given this, such growth must therefore begin from a kind of heap at the start of the process. As we have seen, the 'measure space' of contraries may be comparable to such heaps, as they are explicitly asserted to be measurable by means of the concept of 'one', a discrete unit, and they proceed from a plurality (such as the few) to another plurality (such as the many). It is for this reason that I would call such a space linear, much as a heap of discrete objects is similarly linear, although the implication relationship in reversed: In the Sorites paradox, from the acknowledged linear growth of a heap, it is concluded that the starting point of the heap must be a plurality of some kind. In the case of the analysis of Aristotelian contraries, from the fact that the 'starting point' is acknowledged to be a plurality, not a discrete unity (i.e., the few, not the one), and that its 'growth' (if understood as part of a process of change, as is usually the case) is understood to be capable of discrete measure, follows the conclusion (in terms of my analysis) that such growth must be linear. Furthermore, the assertion that these end 
points are precisely points in a process and not active powers capable of acting on each other directly, further reinforces the analogy.

Thus, I would like to claim that Aristotle's revised analysis of contraries in book Iota sets up what may be not too gratuitously or anachronistically termed a linear measure space, or rather a collection of such spaces, one for each triple of contraries plus measure, a collection of linear spaces of intensive magnitudes.

That there are structural similarities between the above resolution of the sorites paradox (that given discrete, linear growth, the 'one' must be understood to be a measure of, not the starting point of, a heap) and Aristotle's reworking of the relationship between the few, the many, and the one, shows that there may be some sort of logical implicative relationship between linearity and an approach, such as Aristotle's, that tries to account for both discrete and continuous aspects of reality. In the case of the theory of contraries, this combinatory aspect can be seen from Aristotle's three principle approach, as articulated in the earlier work in the first book of the Physics, which attempts to combine both the one and two principle approaches of his predecessors. The combinatory three principle approach to the contraries imputes the same structural features to the resultant intensive 'space' that can be found in the linear space of growth that the Sorites paradoxes explore. In the next section, we will see that the resolution of the Sorites problem in Physics 7.5 may be interpreted in the same manner. However, underneath Aristotle's part-whole approach to the problem (in 7.5), I would contend that its application to the physical reality of the ship hauler problem can only really be made relevant by bringing in causal factors. The analysis of that particular problem is thus worked out in terms of motion and 
rest, which (on the Aristotelian account), are the kinetic equivalents of continuity and discreteness.

The problem of establishing a metric for qualitative spaces has been examined from another angle. Hussey (1983, p.143), for example, uses an argument made by Aristotle in the sixth book of the Physics, at 234 b21-235 b5, and that is roughly that it can be established that qualitative change proceeds in a sort of structural analogy with quantitative change along a path marked out by minimal units or quanta, rather than continuously. In this way, claims Hussey, a natural metric can be set up for qualitative 'phase space' (Hussey’s terminology) in much the same way that it can be for naturally quantitative spaces such as physical space and time.

Yet if qualities can be mapped on to contraries, I would claim that Aristotle's argumentation in book Iota is sufficient to establish this result, without appeal to an underlying physics of motion or the need of a mapping from one to the other. Likewise, the parallel that can be drawn between the analysis of heaps and Aristotle's analyses in book Iota of the one, the few and the many lend further weight to my claim.

A caveat: at this point one might object that measurability needn't imply linearity at all; non-linear spaces (such as the curve of a parabola) can be measured by means of approximation and limits, and such methods of approximation were well-known in antiquity. However, there is a further piece of evidence, and that has to do with status and position of limit entities in measurable spaces. In the largely qualitative spaces of contraries it is difficult to have much insight into what is after all a mathematical concept. It does not make much sense, for example, 
to ask how the dense and rare act as limits beyond the mere fact of being end-points of the rarefaction continuum. Yet there is one domain where such questions can be asked, for Aristotle did treat it quantitatively, or at least sufficiently quantitatively for these questions to be answered, and that is the analysis of motion (kinesis). It is this domain to which we now turn.

\subsection{A mathematization of the measure space: motions and limits}

The crucial features of Aristotle's 'rational kinematics' (White 1992, p. 32) can be summed up as follows ${ }^{28}$ :

A. For Aristotle, a line is not, in contradistinction to the modern perception, made up of or constituted by (an infinite number of) dimensionless points.

B. Motions are continuous and gapless.

C. Although a motion may be identified with the set of places or positions that it passes through, motion does not consist of these positions. Motion is an 'ontologically primitive condition' (White, p. 196).

D. Partition of a movement into segments yields segments which are continuous with each other, in the Aristotelian sense of continuity, i.e., touching immediately, which occurs when the distinct end points of two segments meet ${ }^{29}$.

\footnotetext{
${ }^{28} \mathrm{I}$ am indebted to the discussion in (White, 1992) for most of these points

${ }^{29}$ In contrast to the modern conception, sometimes called 'Dedekind continuity', whereby such touching must occur at the same point. A line with a single non end-point removed is Dedekind discontinuous, but continuous in the ancient sense.
} 
E. Thus, a particular motion is a discrete item, bounded by limit points which are included within it. In other words, a motion is comparable to the modern conception of a closed interval.

F. Such limit points are 'objective but dependent features of the sensible, physical world' (White, p. 207).

For the purposes of the present argument, the most important of these features are the last two. Motion, for Aristotle, is always bounded by limits, the terminus a quo and the terminus ad quem. These termini or end points are the points from which the motion begins and the points where it ends. Like privation and possession, the end points of substantial change, they are achieved or realized within the process of change or motion concerned itself. Motion is always bounded by limits, in particular by an upper limit, or the place of the achievement or stopping point of such motion, but that limit is always reached, unless the motion is interrupted.

Approximative processes, such as, for example, the exhaustion of a series of polygons that gradually approach the limit of a superscribed, or subscribed, circle, do not, in the mathematics of antiquity, ever reach their limit, the said circle. Most ancient Greek mathematicians shared Aristotle's conception that a line was not made up of (an infinite number of) points. Thus, the Greek reaction to Zeno's paradoxes of motion was different from the modern solution. The modern solution concedes that an infinite number of points or stages can fit within a finite interval (either temporal or spatial). For the Greeks this led to paradox, hence the label of 'finitism' familiarly applied to the mathematics of antiquity. This did not mean that approximative procedures were ruled out, only that they could not be seen to end or include their 
limits. Thus, a Greek mathematician would never speak of the summation of an infinite series, as a modern mathematician might. The summation of the infinite series: $1+\frac{1}{2}+\frac{1}{4}+\frac{1}{8}+\frac{1}{2^{n}}+\cdots=$ 2 would make no sense for such a mathematician, who would instead understand the quantity ' 2 ' as the limit of the series, not a quantity that is equal to $\mathrm{it}^{30}$.

If a limit of a motion or series is reached, as in the Aristotelian conception of motion, then, as a consequence, such a motion cannot consist of an infinite series of motions, and $a$ fortiori cannot be an approximative series. Such a space, therefore, must be linear, according to the definition of linearity mentioned above. This is because it is equal to the sum of its components (i.e., segments of motion that it could be potentially divided into), regardless of how these individual components are divided or summed, which we saw above was one of the conditions of linearity. Furthermore, if a space is equal to its components, regardless of how it is divided, then as a consequence such a sum is unique: in other words, given the endpoints of a series (in particular, in the case of motion, the starting point and ending points of motion), there can only be one direct or straight path between the two. The existence of a single path of minimal length between two distinct end points is the very definition of a straight line. We can further conclude that, as there is a single straight line between two points, any two points in a space are thus uniquely correlated by a unique, one-one relation, the straight line that exists between the two.

${ }^{30}$ See White (1992, pp. 137 et seq.) 
It is important to see that linearity followed from Aristotle's assumptions about the nature of continuity and limit points, and was not characteristic of the entirety of ancient thinking about motion and change. The Epicureans, and the Stoics, as White points out, had very different theories of motion, as a consequence of differing conceptions of the reality of continuity and limits.

The Epicurean school, for example, theorized that the natural world consisted of discrete quanta. As a consequence, the second and third points in the list above, that identify continuity and the non-reducibility of motion as primitive qualities of motion, do not characterize the Epicurean conception of motion. Motion, for the Epicureans, is fundamentally a discrete entity, with the result that it cannot be geometrized, for geometry deals with continuous magnitudes. Thus, the concept of a purely linear motion, and with it, the concept of a unique correlation of end points, is likely moot as well ${ }^{31}$, without further assumptions or means of specifying a unique set of quanta that would connect the beginning and end or limits of such a set.

For the Stoics, linearity fails as well, but for the opposite reason. Where the Epicurean universe is wholly quantized, the Stoic world is wholly continuous. The ontology of the Stoics

\footnotetext{
${ }^{31}$ White (p. 250) notes that an Epicurean straight line can deviate sideways by a quanta and remain straight. He also notes that for the Epicureans, non-parallel lines may not intersect, even if extended indefinitely. Both claims undermine the (Euclidean) idea that there is a unique shortest path between points.
} 
accords no place for limit entities. Plutarch reports that (On Common Conceptions 1080E, quoted from Long \& Sedley, p. 299)

Their [The Stoics] favorite objection to the champions of partless magnitudes is that there is contact neither of wholes with wholes nor of parts with parts; for the former produces not contact but blending, while the latter is impossible because partless magnitudes do not have parts. How then do they avoid this trap, seeing that they allow no last or first part? Why, because they say that bodies touch each other by means of a limit, not by means of parts. But the limit is not a body.

If limits are not bodies, in Stoic ontology they could only be incorporeals; yet it is usually acknowledged that the Stoic incorporeal entities consist of only space, time, the void, and socalled 'lekta' or propositions; limits are none of these. Proclus reports ${ }^{32}$ that for the Stoics, limits 'subsist in mere thought'. Limits, for the Stoics, are concepts, not real beings. For the Stoics, every process of change is a gradual process that approaches, but does not reach, conceptual limits, in the same way that ancient mathematical methods of approximation approached, but never equalled, a limiting sum. If limiting sums do not exist (in an equation), then linearity is ruled out.

Such linear spaces are therefore uniquely Aristotelian. It may be difficult to recognize their being so due to the differences between the ancient and the modern conceptions of

32 On Euclid's Elements I, 89, 15-18. Cf. Long \& Sedley (1987), p. 299. 
continuity, and to the common assumption that linear behaviour is usually realized in terms of some form of mechanism. But just as Balme $(1939,1941)$ has demonstrated that theories of matter in motion need not be mechanistic ${ }^{33}$, I would claim, conversely, that theories of being or phenomena that incorporate significant linear elements needn't be realized by reductionist, materialistic theories, as Aristotle's clearly was not. A not uncommon belief that linearity in physics must be a consequence or a condition of the so-called 'Cartesian-Newtonian' paradigm, supposedly exemplified by classical mechanics, blinds us to that fact that the two are conceptually distinct ${ }^{34}$.

I believe that Aristotle's model of linear motion can be conceptually extended to other domains of change in Aristotle, in particular the intensional domains of change studied above, those between other kinds of contraries such as hot and cold, and that they too are, at least potentially, linear domains. Despite the absence of a measurable scale in intentional domains, it can be argued that Aristotle's assumptions remained the same, and that it is at least arguable that should Aristotle have developed the conceptual means of assigning an objective, determinate measure to non-extensional spaces, such as that between hot and cold (temperature), then he

${ }^{33}$ Balme's claim was that ancient atomistic theories differed from their modern counterparts due to the absence of the concept of inertia, with the consequence that the causal determinacy characteristic of modern atomistic theories did not apply in the ancient case.

${ }^{34}$ See note 38 below, for a brief explanation of some of the shared dilemmas faced by Aristotelian and early modern classical mechanics in their attempts to account for both continuous and discrete aspects of reality. 
might have done so. In fact, at the end of Physics VII. 5, Aristotle explicitly claims that proportionality can be established in qualitative alteration (250a 29-33. Tr. Hope (1961, p. 142)).

\begin{abstract}
May we apply these findings also to qualitative alteration, and to increase? In an increase, the effective agent, the subject acted upon, the time, and the amount of increase are all definite. So, too, in a qualitative alteration, there is something definite which does the altering, something definite which is altered, a definite degree of alteration which is completed, and a definite period of time in which the alteration has been effected. If a given period of time is doubled, the amount of alteration will be doubled, and vice versa.
\end{abstract}

All that was missing was an empirical basis for objective measurement, some sort of publicly observable standard, such as existed in the spatial and temporal domains that enabled a clear measure for time and space. For instance, as Duhem has argued (Duhem 1906 pp. 189 et seq.), it was not until the introduction of mercury thermometers that temperature could be given a precise standard of measure, as tubes of mercury enabled the gradual expansion of the volume of mercury in the tube to be correlated with a position on the tube, thus substituting a known metric (length) for a heretofore unknown one. The oft repeated claim that Aristotelian science is inherently qualitative and hence resistant to the kinds of developments familiar from modern science may thus be misguided; its qualitative character may simply be a consequence of the relative undeveloped character of ancient Greek technology, as compared to later scientific and 
technological developments ${ }^{35}$. The difference between quantitative and qualitative fields may thus not be due to the belief that qualities are inherently unmeasurable, but that a publicly observable standard may not (yet?) exist.

At this point, a caveat is in order: the so-called 'ship hauler' problem, discussed by Aristotle in Physics VII.5, might seem to be an issue for the assertion that Aristotelian dynamics is linear. In this part of the Physics, Aristotle, in one of the book's few overtly mathematical discussions, establishes the existence of a proportion between the force applied to an object and the distance moved. Yet he qualifies the statement immediately, claiming that this proportion only applies within limits. If a certain force can cause a certain amount of motion, it does not follow that half of that force can move a proportional amount, either in distance or in time. Otherwise, Aristotle claims, one man may move a ship, a feat which is evidently impossible. Aristotle also explicitly appeals to one of Zeno's sorites paradoxes, the grain of millet paradox, which states that if a heap of grain makes a sound upon falling, then so must each grain; yet no sound is heard from a single falling grain. Aristotle's solution is to deny that a single grain makes a sound, much as a single man cannot haul a ship, though many can.

\footnotetext{
${ }^{35}$ Archytas (a contemporary of Plato) reports (according to Simplicius) three kinds of quantitative measures: those of number, extension, and weight (Sambursky, p. 83). Sambursky credits this recognition to the existence of three basic techniques of measurement: enumeration, the yardstick, and the balance.
} 
Linearity appears to have limits; forces and other alterations may be additive, but only within certain boundaries. What are we to make of this situation?

Sambursky (p. 64) claims that these hedges were due to the absence of a theory of friction. A certain minimum amount of force is required to overcome opposing frictional forces, but as there was little understanding of the actions of frictional forces in antiquity, other solutions had to be found. Hence the idea of inherent limits to the additivity of forces.

The presence of frictional forces is undoubtedly the correct explanation of certain cases of the phenomena, especially of the example in question (the ship haulers), but this explanation fails to account for the wider range of cases where no frictional forces are present, including the example of the millet seed paradox, cited by Aristotle as a case with explanatory relevance to case of the ship haulers.

Sambursky also cites material drawn from the commentaries on the Physics by Themistius and John Philoponus. Both commentators speculate that when separate forces act together, their combined power is greater than would be the case were they to act individually on a similarly divided object. Themistius uses the example of a team of horses pulling a chariot, and his explanation is blatantly psychological (an increase in team spirit is responsible for the greater force), but he also uses a geometrical example: two unit squares added together have a smaller area than that of one two-unit sided square. Philoponus claims that a weight divided into two equal parts will yield two parts each of less than half the weight of the total. In other words, 
forces (including weight) are non-additive; combined, they are more than the sum of their parts, and divided, their sum is less than their total force when united.

Sambursky (p. 68) comments that this idea, that forces, when combined, have a greater power than the sum of their parts, belies a clear influence of Stoic notions. For as we have seen, for the Stoics limits did not have real existence; as a consequence, every process of change involved more than the summing of it stages once the change was completed, and in a similar way, the combination of parts into a cohesive whole involved a combining 'tension' (tonos) that added to the materiality of the combination.

Yet we can be sure that Aristotle would have rejected these explanations, save for the cases where a single measure of force has no apparent effect. For in a passage immediately following the discussion of the ship hauler problem, Aristotle claims that, as long as the effects of individual forces are greater than zero, their combined capacity will be summative (250a 2528). Thus, within certain limits or thresholds, which likely bound the greater part of phenomena, linearity is simply a fact of experience.

If neither frictional forces, nor the non-additivity of forces are acceptable explanations, how can the ship hauler problem be resolved? Berryman (pp. 190-1) notes that Simplicius accepted the postulation of natural limits to the potency of forces. She attributes Simplicius' acceptance of thresholds in nature to the anti-reductionist perspective of Neo-Platonism. I doubt that this perspective could have been Aristotle's, however. I would conjecture that Aristotle needed to postulate thresholds in order to limit the chains of causal influence. Without 
thresholds, potential causal influence becomes unlimited in extent and as we know Aristotle rejects the idea of infinite chains of causality.

If forces behave in a linear fashion, then there must be real thresholds to the power of forces, otherwise (for Aristotle) stability will turn out to be impossible. The ship hauler problem in particular involves motion, the motion of the dragged ship. As we have seen, for Aristotle, motion comes in discrete units: a motion has a beginning and an end, which is always achieved (except for the unique case of circular motion, which is confined, however, to the celestial realm). If the slightest force could have an impact on the motion of the docked ship, then the motion of the ship would never come to an end, or rather, the moment one motion of the ship ceased, another would take its place. All things would be in constant, continuous motion, especially the more so if there is, as in the Aristotelian cosmos, no void that separates objects from others. Every object will be in constant contact with moving objects; even the smallest and slowest of these will have some sort of causal influence on its neighbours. It would be impossible to entirely isolate an entity from its environment, for, surrounded by it, an entity will be constantly be casually influenced by its surroundings. Consequently, limits or thresholds need to be postulated to explain the observed (or, perhaps, postulated) facts of the universe: that stability exists $^{36}$, that entities can be causally isolated from their environment, and that causal chains need not be infinite, the latter which would render explanation impossible.

\footnotetext{
${ }^{36}$ Aristotle does not appear to make the above causal-reductio argument explicitly. But an identical conclusion can be arrived at as follows: As all change involves locomotion (Physics VIII 7 260a 20-261a26), and periods of rest must exist-Point E, section 2.2 above, implies that
} 
Thus, the significance of the paradox of the millet seed to the ship hauler problem may phrased in the following way: from the observed fact of the existence of individual physical events that do not make a sound while a collectivity of them does, it is concluded that there must be natural thresholds in the potency of physical forces. In a parallel way, in the case of the ship: a single ship hauler's inability to move a ship is taken as empirical confirmation of the theoretically postulated existence of rest due to the need for finite chains of causal explanation, while the empirical fact that a group of ship haulers can move a ship shows that together such forces can cause movement; from these postulates it is concluded that such forces must have natural thresholds. In short, because stability exists (rest, absence of sound), there must be limits in nature. Although Aristotle appears to address the paradox as a part-whole argument ${ }^{37}$, this must be the actual causal explanation behind the ship hauler problem itself in Aristotle's argument, which his language of part and whole tends to conceal.

there must exist intervals of rest between motion segments (cf. White, p. 46) - then the entirety of the (sub-lunar) cosmos cannot be in constant continuous change. Hence, "Those physicists are clearly in error, then, who declare all sensible things to be in constant motion." (Physics VIII 8 265a3-4, tr., Hope).

${ }^{37}$ For which see Wardy (1990), pp. 323-326, who interprets Aristotle's use of the paradox as a demonstration of the impossibility of decomposing forces into components. 
The Stoics were able to account for stability by means of the notions of tension (tonos) and containing causes (aitia synektika), but these options were not available to Aristotle ${ }^{38}$. Although form is sometimes taken to be kind of guarantor of stability in the Aristotelian universe, because it serves as a foundation of the identity of substances, I would contend that this is so only for concrete particular 'things', and not for patterns of interaction, which are instead stabilized by the kind of linearity, and the presence of thresholds, just mentioned. We will see below, also, that linearity may even lie behind the stability of primary things, i.e. substances.

\subsection{The dimensionless space of composite being: the unity of matter and form}

In the last chapter of book Eta of the Metaphysics, Aristotle sums up his discussion of the unity of matter and form in the following (tr. Ross, in Barnes (ed.) (1984)).

\footnotetext{
${ }^{38}$ It is sometimes forgotten that the classical mechanics of the $17^{\text {th }}$ and $18^{\text {th }}$ centuries faced similar dilemmas, and that its initial solutions may be said to resemble the Aristotelian solution, although pushed into the micro-level, out of the 'manifest image'. The paradoxes generated by both rigid body and elastic body mechanics are well known (the need to postulate infinite forces at the moment of collision, and problems that arise when attempting to account for the deformations of homogenous partless bodies, respectively). These problems are likely unavoidable for any theoretical approach that tries to account for both continuous and discrete aspects of reality. Classical mechanics only began to avoid these problems with Boscovich's postulation of dimensionless 'point atoms', surrounded by fields of force. In eliminating discrete atomic elements, whether rigid or elastic, Boscovich's solution is reminiscent of the Stoic approach. For an overview, see M. Wilson (2013) and W. Scott (1959).
} 
The proximate matter and the form are one and the same thing, the one potentially, the other actually. Therefore to ask the cause of their being one is like asking the cause of unity in general; for each thing is a unity, and the potential and the actual are somehow one.

How are we to understand this? 'One', like 'being', can be said in many ways, as Aristotle repeatedly reminds us. A collection of items can be one, but so can a point or a number, and their unity differs in the way that their being does. But what sort of unity is involved here? In order to answer this, we must back up a bit and glance back at a passage in H 3: (1043b 25-30, 1044a 810. tr. Hope)

What is cannot be defined, since a definition is merely talk and tells only of what kind a thing is; for example, they [the followers of Antisthenes] thought it impossible to tell what silver itself is, but merely that it is like tin. Hence, the only kind of primary being of which there may be definition and explanation is the composite, whether it be perceptible or intelligible; but of their primary constituents there can be none, since a definition relates something to something [...] a primary being is united as we have explained, not, as some say, by being a sort of unit or point; each is rather an integration (entelecheia) and a nature. 
What constitutes the unity of substance? If an answer is to be given, substance must be understood to be composite, for simple natures can neither be defined nor explained. In what way? As in a definition, where something is related to something, definiendum to definiens. In $\mathrm{H}$ 6, Aristotle examines the relation or bond between matter and form, and rejects a number of possibilities that might explain their union : synousia (union, marriage, communion), synthesis (combination, composition, addition), syndesmos (bond, fastening). Those who postulate these kinds of bonds attempt to show, claims Aristotle, how the potentiality and realization found in matter and form are 'both one and different' - an explanatory step Aristotle appears to approve of. But this extra step is not necessary to explain the unity of substance, claims Aristotle, because potentiality and actuality are both one and different in and of themselves. Nothing else needs to be added to link them together.

However, although in substance (proximate) matter and form are together 'one and the same', they are not identical, as some interpreters have claimed. Now, this must be because if they were in fact identical, they would together constitute something simple, 'like a unit or a point', but this they cannot be $\mathrm{b}^{39}$.

${ }^{39}$ Thus, Hope's (1951, p. 180) use of the phrase 'two aspects of the identical reality', which he


incorrect, for 'aspects' implies that there is only a notional difference between the two. 
This is the point defended by Keeling (2012), in rejection of what he calls the 'identity model' of unity, and what Galluzzo \& Mariani (2006, p. 112 et seq.) call the 'projectivist' view, associated with Wilfrid Sellars, among others. Keeling uses the term 'correlative' to explain the unity of matter and form within substance. As Keeling ( p. 251) explains (italics original),

While no cause (other than the efficient one) is needed to account for the unity of matter and form, understanding this unity requires understanding the reciprocal nature of matter and form $[\ldots]$ The potential and the actual sphere [in the example of the bronze sphere] can be understood as the essence of the other. Aristotle's point is not that the potential and actual spheres share the same nature - that of the form. Their natures are not the same; they are correlative: the bronze of a bronze sphere is by its nature the matter of that sphere, while the spherical shape is by its nature the form of it. The two are by their very nature united with one another [...] Taking matter and form in this way, their compresence is sufficient to guarantee the unity of the composite object.

Like definiendum and definiens, matter and form connect together in and of themselves, without the need for a further relational link. In Keeling's terminology, they form a 'correlative' pair, and are 'compresent', present together. 
We have seen that contraries are correlative beings. Likewise, the end points of motion form a pair ${ }^{40}$ of points correlated by a line. The line links the two points, but is also constituted by the set of two points, as a straight line is defined as the shortest path between two points, and thus is nothing in addition to them. Proximate matter and form might be seen as two points in a sort of conceptual space of becoming, but in this case the points are immediately proximate, with no space between them, or in other words, touching. As we have seen (n. 29, above), according to the ancient conception of continuity, two objects separated by a dimensionless point are regarded as touching one another, and hence continuous with each other. This is in contrast to the modern conception, in which the removal of a point creates discontinuity. Objects that are correlative in this way (and that are homogenous in the way that matter and form, by taking part in the same definition of substance, are), therefore, can be called 'one and the same', in the sense that there is no break in continuity. They are not identical, but sequential and touching (as whatever is touching is also sequential or in succession, as Aristotle remarks at 227a 20), and hence may be called the 'same' due to their continuity in both kind and succession.

\section{Conclusion: The Linearity of Being and the Unity of Metaphysics}

Thus, I believe I have shown how the model of a linear metric space can help us understand, not simply Aristotle's analysis of the quantitative domain of motion, but, abstracting from a concrete

\footnotetext{
${ }^{40}$ Circular motion, the other kind of simple motion recognized by Aristotle, is an exception. In this case, the two points are identical. Circular motions form a special case, which can be left aside for the present.
} 
exemplar of measurement, the qualitative domain of his theory of contraries, which if we are to take the claims of book Gamma and Lambda seriously, remain important for his metaphysics. As well, I have tried to show how this model can be extended even to the analysis of the dimensionless domain of the unity of matter and form, and therein to the heart of Aristotle's metaphysics, the theory of substance.

In conclusion, and in contrary to the emphases of certain contemporary interpretative trends, I would argue that linearity in metaphysics, which includes the rejection of real many-one relations, and their replacement with one-one relations, is what distinguishes Aristotle's thought from that of both his predecessors and his immediate successors. 


\section{References}

Annas, J. (1976). Aristotle’s Metaphysics: Books M and N. Oxford: Clarendon Press

Aubenque, P. (1962). Le problème de l'être chez Aristote. Paris : Presses Universitaires de France.

Barnes, J. (ed.) (1984). The Complete Works of Aristotle. Princeton: Princeton University Press.

Balme, D. (1939). 'Greek Science and Mechanism, I : Aristotle on Nature and Chance'. The Classical Quarterly, 33 (3, 4), 129-138.

$(1,2), 23-28$.

Berryman, S. (2009). The Mechanical Hypothesis in Ancient Greek Natural Philosophy. Cambridge: Cambridge University Press.

Castelli, L. (2010). Problems and Paradigms of Unity: Aristotle's Accounts of the One. Sankt Augustin: Academia Verlag.

- (2018). Aristotle: Metaphysics Book Iota. Oxford: Clarendon Press.

Charlton, W. (1970). Aristotle’s Physics: Books I \& II. Oxford: Clarendon Press.

Crubellier, M. (1997). 'La beauté du monde : les sciences mathématiques et la philosophie première'. Revue Internationale de Philosophie, (51), 307-331.

- (2005). 'Les faits ontologiques et leur causes'. In M. Narcy \& A. Tordesillas, (eds.) La "Métaphysique” D’Aristote : Perspectives Contemporaines. Paris: Vrin; Brussels, Ousia, 59-80.

De Groot, J. (2014). Aristotle's Empiricism: Experience and Mechanics in the $4^{\text {th }}$ Century B.C. Las Vegas: Parmenides.

Delcomminette, S. (2019). 'Physics I 5: Principles and Contraries'. In K. Ierodiakonou, P. Kalligas, \& V. Karasmanis (eds.) (2019), Aristotle's Physics Alpha (Symposium Aristotelicum 20). Oxford: Oxford University Press, 156-189.

Duhem, P. (1906). La théorie physique : son objet et sa structure. Paris : Chevalier \& Rivière.

Frede, M. (1987). 'The title, unity, and authenticity of the Aristotelian Categories'. In (ibid.), Essays in Ancient Philosophy. Minneapolis: University of Minnesota Press, 11-28. 
Furth, M. (tr.) (1985). Aristotle: Metaphysics: Books Zeta, Eta, Theta, Iota. Indianapolis: Hackett.

Galluzzo, G. \& Mariani, M. (2006). Aristotle’s Metaphysics Book Z: The Contemporary Debate. Pisa: Edizioni Della Normale.

Hope, R. (tr.) (1952). Aristotle: Metaphysics. New York: Columbia University Press.

_ (tr.) (1961). Aristotle’s Physics. Lincoln: University of Nebraska Press.

Hussey, E. (1983). Aristotle’s Physics: Books III \& IV. Oxford: Clarendon Press.

Jaeger, W. (1957). Aristotelis Metaphysica. Oxford: Clarendon Press.

Judson, L. (2018). 'Physics I.5', In D. Quarantotto (ed.) (2018), Aristotle's Physics, Book I. A Systematic Exploration. Cambridge: Cambridge University Press, 130-153.

(2019). Aristotle: Metaphysics Book A. Oxford: Clarendon Press.

Keeling, E. (2012). 'Unity in Aristotle’s Metaphysics H 6'. Apeiron, (45), 238-261

Lefebvre, D. (2008). 'L'usage de la série des contraires en Métaphysique Г 2, 1004b27-1005a6', In M. Hecquet-Devienne and A. Stevens (eds.) (2018), Aristote : Métaphysique Gamma. Édition, traduction, études. Louvain-La-Neuve : Peeters, 287-321.

Lennox, J. (2001). Aristotle's Philosophy of Biology: Studies in the Origins of Life Science. Cambridge: Cambridge University Press.

Long, A. A. \& Sedley, D.N. (eds.) (1987). The Hellenistic Philosophers: Vol. 1. Cambridge: Cambridge University Press.

Lorenz, H. (2020). 'Physics I 7, Part 2: The Principles of Natural Things-Two or Three?'. In K. Ierodiakonou, P. Kalligas, \& V. Karasmanis (eds.) (2019), Aristotle's Physics Alpha (Symposium Aristotelicum 20). Oxford: Oxford University Press, 262-285.

Morel, P-M. (2015). Aristote : Métaphysique, Livre Èta. Introduction, traduction et commentaire. Paris : Vrin.

Morison, B. (2019). 'Physics I.7, Part I: The Complexity of the Subject in Change'. In K. Ierodiakonou, P. Kalligas, \& V. Karasmanis (eds.) (2019), Aristotle's Physics Alpha (Symposium Aristotelicum 20). Oxford: Oxford University Press, 229-261.

Ross, W.D. (ed.) (1936). Aristotle's Physics. A revised text with introduction and commentary. Oxford: Clarendon Press. 
Sambursky, S. (1962). The Physical World of Late Antiquity. Princeton: Princeton University Press.

Scott, W. (1959). 'The Significance of "Hard Bodies" in the History of Scientific Thought', Isis, 50 (3), 199-210.

Simplicius, (2012) [c. 500]. On Aristotle's Physics 1.5-9, Han Baltussen, Michael Atkinson, Michael Share, and Ian Mueller (trans.), London: Bloomsbury.

Truesdell, C. (1968). Essays in the History of Mechanics. Berlin: Springer.

Wardy, R. (1990). The Chain of Change: A Study of Aristotle's Physics VII. Cambridge: Cambridge University Press.

White, M. J. (1992). The Continuous and the Discrete: Ancient Physical Theories from a Contemporary Perspective. Oxford: Clarendon Press.

Wilson, M. (2013). 'What is “Classical Mechanics”, Anyway?', In R. Batterman, (ed.) The Oxford Handbook of Philosophy of Physics. Oxford: Oxford University Press, 43-106.

Wolff, F. (2005). 'Qu'est-ce que se demander ce qu'est la réalité?'. In M. Narcy \& A. Tordesillas, (eds.) La "Métaphysique” D’Aristote : Perspectives Contemporaines. Paris: Vrin; Brussels, Ousia, pp. 145-170.

Zingano, M. (2005). 'L'ousia dans le livre Z de la Métaphysique', In M. Narcy \& A. Tordesillas, (eds.) La "Métaphysique” D’Aristote : Perspectives Contemporaines. Paris: Vrin; Brussels, Ousia, pp. 99-130. 